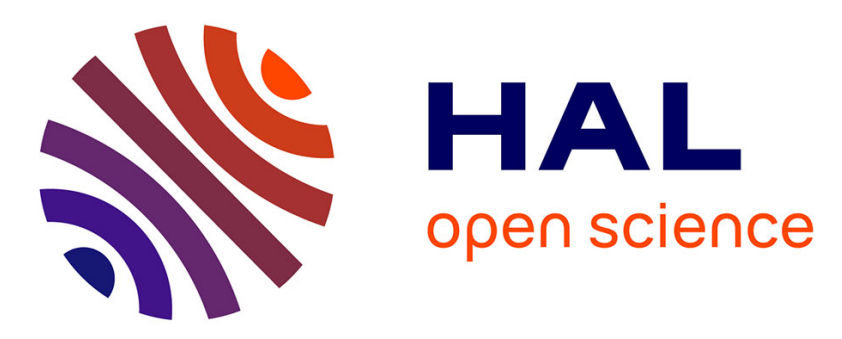

\title{
Effects of processing on pesticide residues in peaches intended for baby food
}

\author{
Anna Balinova, Rosica Mladenova, Deyana Shtereva
}

\section{To cite this version:}

Anna Balinova, Rosica Mladenova, Deyana Shtereva. Effects of processing on pesticide residues in peaches intended for baby food. Food Additives and Contaminants, 2006, 23 (09), pp.895-901. 10.1080/02652030600771715 . hal-00577485

\section{HAL Id: hal-00577485 \\ https://hal.science/hal-00577485}

Submitted on 17 Mar 2011

HAL is a multi-disciplinary open access archive for the deposit and dissemination of scientific research documents, whether they are published or not. The documents may come from teaching and research institutions in France or abroad, or from public or private research centers.
L'archive ouverte pluridisciplinaire HAL, est destinée au dépôt et à la diffusion de documents scientifiques de niveau recherche, publiés ou non, émanant des établissements d'enseignement et de recherche français ou étrangers, des laboratoires publics ou privés. 


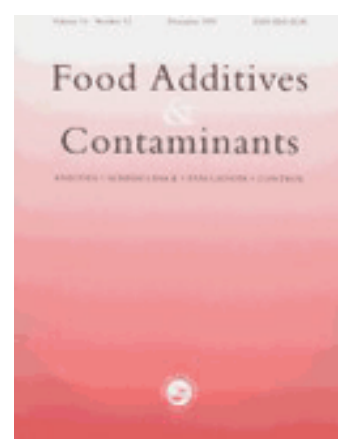

\section{Effects of processing on pesticide residues in peaches intended for baby food}

\begin{tabular}{|c|c|}
\hline Journal: & Food Additives and Contaminants \\
\hline Manuscript ID: & TFAC-2006-001.R2 \\
\hline Manuscript Type: & Original Research Paper \\
\hline $\begin{array}{r}\text { Date Submitted by the } \\
\text { Author: }\end{array}$ & 09-Apr-2006 \\
\hline Complete List of Authors: & $\begin{array}{l}\text { Balinova, Anna; Plant Protection Institute, Toxicology } \\
\text { Mladenova, Rosica; Plant Protection Institute, Toxicology } \\
\text { Shtereva, Deyana; Plant Protection Institute, Toxicology }\end{array}$ \\
\hline Methods/Techniques: & Exposure assessment \\
\hline Additives/Contaminants: & Pesticide residues \\
\hline Food Types: & Baby food \\
\hline
\end{tabular}

\section{SCHOLARONE Manuscripts}




\section{EFFECTS OF PROCESSING ON PESTICIDE RESIDUES IN}

2 PEACHES INTENDED FOR BABY FOOD

3

4 Anna M. Balinova, Rositsa I. Mladenova and Deyana D. Shtereva

5

6 Department of Toxicology, Plant Protection Institute, Kostinbrod 2230, Bulgaria

7

$8 \quad$ Corresponding author:- abalinova@abv.bg 


\section{Abstract}

2 Peaches containing incurred residues of chlorpyrifos-methyl, fenitrothion, procymidone

3 and vinclozolin were used for simulated industrial processing to manufcature baby food

4 puree. The residues were determined in raw material, in intermediate products at crucial

5 steps of the processing procedures and in final products. The determination of the residues

6 was performed by an analytical method distinguished by high sensitivity based on acetone

7 extraction, 2 steps clean-up/pre-concentration on graphitized carbon and SAX/PSA

8 sorbent and GC-ECD. The results of the study were interpreted with respect to

9 enforcement of the stringent Maximum Residue Limit of $0.01 \mathrm{mg} \cdot \mathrm{kg}^{-1}$ established by

10 European Commission (EC) for any pesticide in baby food. Peeling was identified as the

11 most effective procedure resulting in reduction of residues. Thermal treatment

12 (concentration and sterilisation) contributed to substantial reduction of organophosphate

13 (chlorpyrifos-methyl, fenitrothion) residues, but procymidone and vinclozolin residue

14 levels were increased by peach puree thermal concentration.

Key words: pesticide residues, chlorpyrifos-methyl, fenitrothion, procymidone,

17 vinclozolin, peaches, processing, baby food 


\section{Introduction}

3 The risk assessment of dietary intake of pesticides is important for ensuring safe food

4 production (Lentza-Rizos 2001). Special attention should be given to the health protection

5 of babies and small children, as they are the most vulnerable group of population

6 (Matsumura 2004, Dencker et al. 1998). In order to protect the health of infants and small

7 children in the European Union (EU), very strict limit has been introduced by the

8 European Commission (EC) for any pesticide potentially occurring in baby food. 
1 peaches. The EU MRLs established for peaches intended for general nutritional uses are 2

$2 \mathrm{mg} / \mathrm{kg}$ for procymidone, $0.5 \mathrm{mg} / \mathrm{kg}$ for chlorpyrifos-methyl and fenitrothion and 0.05

$3 \mathrm{mg} / \mathrm{kg}$ for vinclozolin (European Commission 2002). The existence of international

4 MRLs indicates that the corresponding pesticides are authorised to be used on particular

5 crops and that detectable residues of the order of magnitude of the MRL are left at

6 harvest. Pesticides with international MRLs of the order of $0.01 \mathrm{mg} \cdot \mathrm{kg}^{-1}$ were not

$7 \quad$ included in the study with the exception of pesticides of high frequency of occurrence of

8 samples with residues exceeding MRLs (monitoring studies).

9

The enforcement of the very stringent Directive on residues in baby food makes it necessary to understand the behaviour of pesticides during processing. Optimisation of all technological parameters would allow final products to be prepared in compliance with baby food safety requirements after processing of potentially contaminated raw materials.

The aim of this work was firstly to study the effect of fruit processing procedures on behaviour of chlorpyrifos-methyl, fenitrothion, procymidone and vinclozolin residues in peaches intended for production of baby food puree. Secondly, the aim was to establish the processing factors for intermediate and final products of simulated industrial and household processing of peaches, treated with the selected pesticides. Thirdly we aimed to contribute to refinement of the plant protection technologies and processing technologies in order to guarantee production of baby food in compliance with the particular safety requirements.

The MRL for residues established in baby food is 10 -100 times below the MRLs for food of general consumption. This very low limit necessitates considerable attention to be paid 
1 to the problems of assurance the high quality of analytical methods both in respect of

2 quantitative parameters (sensitivity, trueness, precision, and range) and of qualitative

3 assessment (identification and confirmation). Implementation of analytical methods

4 capable of determining the pesticide residues at ultra-trace levels (at or below $0.01 \mathrm{mg} \cdot \mathrm{kg}^{-}$

$5{ }^{1}$ ) was mandatory in the study.

6

7

\section{Materials and methods}

Chemicals and apparatus. Acetone, ethyl acetate and methanol (gas chromatography grade) were obtained from Merck KGaA (Darmstadt, Germany). Solid phase extraction (SPE) sorbents: graphitized carbon ENVI-Carb 120/400 mesh, surface area $100 \mathrm{~m}^{2} \cdot \mathrm{g}^{-1}$, was obtained from Supelco (Bellefonte, PA, USA); Bond Elute SAX 250 mg-PSA 250 mg was from Varian Inc. (Lake Forest, CA 92630 USA). Certified analytical standards of chlorpyrifos-methyl, fenitrothion, procymidone and vinclozolin were obtained from Dr. Ehrenstorfer (Augsburg, Germany). Stock solutions $\left(1.0 \mathrm{mg} \cdot \mathrm{ml}^{-1}\right)$ of each pesticide were prepared in ethyl acetate and stored in a freezer. Working standard solutions at concentration rates of $5 \mathrm{ng} \cdot \mathrm{ml}^{-1}-500 \mathrm{ng} \cdot \mathrm{ml}^{-1}$ were prepared by diluting of stock solutions with ethyl acetate and stored at $4^{\circ} \mathrm{C}$ in dark. Double distilled water was used when needed in experiments. Filter paper "blue spot 391", fine-pored, was obtained from Sartorius AG, Goettingen, Germany.

A Hewlett-Packard gas chromatograph Model 5890 Series II equipped with ${ }^{63} \mathrm{Ni}$ electron capture detector (ECD) was used. Split-splitless injector operated in the splitless mode. Capillary column AT ${ }^{\mathrm{TM}}-5 \mathrm{~ms},(30 \mathrm{~m} \times 0.25 \mathrm{~mm} \times 0.25 \mu \mathrm{m})$ was obtained from Alltech Associates, Inc. (Lokeren, Belgium). The purity of nitrogen used was greater than 99.999 $\%$ (SIAD, Bulgaria). Vacuum manifold (Varian Inc) was used for SPE. 
2 Field treatment and sampling. The field treatments of peach trees cultivar Fayette with

3 the commercial formulations Reldan 50 EC (chlorpyrifos-methyl 500 g.l ${ }^{-1}$ active 4 ingredient (a.i.) and Sumilex 50 WP (procymidone 500 g.kg ${ }^{-1}$ a.i.) were carried out in the 5 orchard belonging to the experimental station on peaches near the town of Sliven on 22 6 August 2003. The field treatments with the commercial formulations Agria 1050 7 (fenitrothion 500 g. l $^{-1}$ a.i.) and Ronilan (vinclozolin 500 g. $\mathrm{kg}^{-1}$ a.i.) were carried out in the 8 orchard of the experimental station near the town of Petrich on 10 September 2004.

All pesticides were applied at the recommended rate of $0.15 \%$ a.i. by using common orchard spraying equipment. Each pesticide working solution was applied on four trees and three trees received no treatment (control trees). Samples were collected 3 days after treatment. The aim was to obtain fruits containing incurred residues at concentration high enough to be traced in all intermediate products and in the final products of the simulated industrial processing to baby food puree. $40 \mathrm{~kg}$ of peaches were collected of each variant of treatment and of the untreated control trees. The sampling was carried out according to the recommendations of the EC for residue analysis sampling (European Commission 2002).

Processing procedures. All processes applied to the study for processing effects assessment were planned in a way to correspond as closely as possible to those that occur in actual practice. The field samples of each pesticide/peach combination were put into polyethylene bags and immediately transported to the laboratory. The following sets of samples of each type were prepared for processing and pesticide residues analysis:

- Fruits, without washing 
- Fruits, to be submitted to washing with tape water

- Fruits, to be submitted to mechanical peeling after washing

- Fruits, to be submitted to chemical peeling after washing

Approximately $3 \mathrm{~kg}$ of whole fruits were taken of each type. The stones were removed from the fruit selected to be analysed without washing. The weights of the edible part and of the stones were taken. The samples selected to be analysed after washing were intensively washed with tap water and processed as described above. The washed fruits were divided into two sub-samples and submitted to different types of peeling: mechanical, typical for household processing and chemical, applied mostly in industrial processing. The weights of the edible part of the fruits, stones and peels of mechanically peeled fruits were taken. The peel of mechanically peeled fruit were weight separately. The edible parts of the fruit were blended and stored in plastic bags in a freezer at $\left(-23^{\circ} \mathrm{C}\right)$ for simulated industrial processing and analyses.

The processing procedures were carried out under the following conditions: washing with tap water at $16^{\circ} \mathrm{C} \pm 2{ }^{0} \mathrm{C}$; chemical peeling with $4 \% \mathrm{NaOH}$ solution at $90^{\circ} \mathrm{C}$, then after removing the peel - $2 \%$ citric acid solution and washing with water; concentration by boiling under open conditions at $90^{\circ} \mathrm{C} \pm 2^{0}$ to $24 \% \pm 1.7 \%$ dry content; thermal sterilisation in closed jars at $90^{\circ} \mathrm{C} \pm 2^{0}$ for $25 \mathrm{~min}$.

At each crucial step of the processing procedure samples were taken and submitted to residue analysis. All procedure steps and corresponding samples taken for analysis were given consecutive numbers as presented in figure 1.

[Fig.1 here] 
2 Analytical method.

3 Extraction: Analytical samples (10 g) of the thoroughly homogenised material were

4 weighed and taken at the selected steps of the processing procedure. Acetone $(20 \mathrm{ml})$ was

5 added and samples were extracted by mechanical shaking for $30 \mathrm{~min}$. Extracts were

6 filtered, residues washed by shaking with $2 \times 20 \mathrm{ml}$ acetone, and filtrates combined and

7 homogenised. A half of the volume of each mixed filtrate was taken for further SPE

$8 \quad$ clean-up and pre-concentration.

9 Sample clean-up. The aliquots of the acetone extracts (approximately $25 \mathrm{ml}$ ) were diluted 10 with doubly-distilled water $(200 \mathrm{ml})$ and the diluted extracts were submitted to two step 11 SPE clean-up/preconcentration. The first step of SPE was carried out by using 12 polypropylene cartridges manually packed with $400 \mathrm{mg}$ ENVI-Carb, conditioned with 10 13 ml ethyl acetate: methanol (8:2) followed by $5 \mathrm{ml}$ methanol and washed with $10 \mathrm{ml}$ water. 14 The sorbent was never allowed to dry during the conditioning and sample loading steps.

15 The samples were forced to pass through the sorbent under vacuum at rate of $10 \mathrm{ml} \cdot \mathrm{min}^{-1}$. 16 After the passage of the sample, the sorbent was washed with $0.4 \mathrm{ml}$ methanol and dried 17 under vacuum for $30 \mathrm{~min}$. The pesticides were eluted with $6 \mathrm{ml}$ ethyl acetate-methanol $18(8: 2)$ at rate of $1 \mathrm{ml} / \mathrm{min}$ and collected in $10 \mathrm{ml}$ graduated tubes. The eluates were 19 submitted to the second clean-up step by using SAX-PSA Bond Elut cartridges. The sorbent was washed with $2 \mathrm{ml}$ methanol and conditioned with $2 \mathrm{ml}$ ethyl acetate-methanol 21 (8:2). The samples were passed through the cartridge at rate of approximately $1 \mathrm{ml} \cdot \mathrm{min}^{-1}$. After the passage of the sample, the elution of the analytes was completed by washing 23 twice with $1 \mathrm{ml}$ ethyl acetate-methanol (8:2). Combined eluates were collected in $10 \mathrm{ml}$ 24 graduated tubes. The initial volumes of the samples were adjusted at $5 \mathrm{ml}\left(1 \mathrm{~g}\right.$ matrix.ml $\left.\mathrm{ml}^{-1}\right)$ by evaporation under gentle stream of nitrogen. Samples containing high-level residues 
1 (unpeeled fruits, peels) were diluted to bring them within the calibrated range. Samples

2 containing low-level residues (peeled fruits, puree of peeled fruits) were concentrated to

3 bring the residue levels at or over the lowest calibrated level.

4 Chromatographic conditions. GC-ECD operating conditions: carrier gas nitrogen, at flow

5 rate $2.5 \mathrm{ml} \cdot \mathrm{min}^{-1}$; make up nitrogen $30 \mathrm{ml} \cdot \mathrm{min}^{-1}$; injector temperature $270^{\circ} \mathrm{C}$, splitless

6 time $1.5 \mathrm{~min}$; detector temperature $300^{\circ} \mathrm{C}$. Oven temperature program: $100^{\circ} \mathrm{C}$, hold $1 \mathrm{~min}$; rate $20^{\circ} \mathrm{C} / \mathrm{min}$ to $260^{\circ} \mathrm{C}$ final temperature, hold $3 \mathrm{~min}$. Injection volume was $1 \mu \mathrm{l}$ for all samples. Quantification was performed by using external standards. Matrix-matched calibration standards were used for all quantifications.

Preparation of matrix-matched calibration standards. Blank extracts of each type of samples were submitted to SPE clean up as described above. Series of standard solutions were prepared by adding $0.1 \mathrm{ml}$ of pesticide standards of desired concentration to cleaned extracts aliquot to $5 \mathrm{~g}$ blank matrix and the volumes were adjusted to $5 \mathrm{ml}$. In cases when final sample extracts were diluted or concentrated the matrix extracts in calibration standards were adjusted in order to ensure similar matrix concentration in sample and standard solutions.

\section{Results and Discussion}

\section{Method validation}

The method was validated for peaches. The linearity of ECD response was determined in the range of $0.005 \mathrm{ng}-0.05 \mathrm{ng}$. The correlation coefficients $\mathrm{r}^{2}$ of the four pesticides studied were higher than 0.98 (five-point calibration curve). Concentrations of the analytes in the samples were calculated by using single-level calibration method. This approach is recommended in case the detector response is variable with time (Document SANCO/10476/2003). In our studies it was confirmed that single-level calibration gave 
1 more accurate results than multi-level calibration when the analytes concentrations in

2 samples were adjusted in an interval $\pm 10 \%$ of the calibration level used.

3

4 The mean recoveries and the repeatability expressed as standard deviation (SD),

[Table 1 here]

The lowest calibrated levels were adopted at $0.005 \mathrm{mg} / \mathrm{kg}$ for chlorpyrifos-methyl, procymidone and vinclozolin and at $0.01 \mathrm{mg} / \mathrm{kg}$ for fenitrothion. The limits of quantification (LOQ) were specified at these concentration levels because it ensured compliance with European Commission criteria for quantitative residue methods (Document SANCO/10476/2003). The LOQ values of the compounds confirmed that the method was suitable for analyses of these residues in baby food for compliance with the EU MRL. The combination of graphitized carbon (Envi-carb) and quaternary amine/primary-secondary amine (SAX-PSA) results in a clean-up that removes a wide spectrum of matrix co-extractives. Graphitized carbon in reversed-phase mode effectively removes pigments and sterols. Quaternary amine/primary-secondary amines are effective in retention of fatty acids, organic acids and some sugars. The applied two-step clean-up procedure by using sorbents of different mechanisms of action helped to reduce the matrix enhancement effect and avoid contamination of the GC system. It resulted in a decrease of the base line noise and increase of the sensitivity expressed as signal-to-noise ratio. Chromatograms of pure standards, blank sample and blank sample fortified for determination of recovery, presented in figure 2, show the efficiency of the clean-up procedure applied. 
[Fig.2 here]

3

[Table 2 here].

The extent and direction of the processing effects are expressed by Processing Factors (P) defined as a ratio between residues in processed commodity (PC) and raw commodity (RC). Values of $\mathrm{P}<1$ indicate that residues undergo processes of dilution/degradation and values of P>1 - processes of concentration (Joint Meeting on Pesticide Residues 2000). Processing factors calculated for the individual procedures and for the entire processing are presented in table 3.

[Table 3 here].

The key factors for the effectiveness of washing in reduction of residue concentration are the age of the residues and the mode of action (systemic or non-systemic). Sampling was 
1 carried out 3 days after treatment in order to obtain residues incurred into cuticular waxes

2 or deeper for closely simulating the processes in actual practice. The results presented in

3 table 3 show that the cold water washing is a procedure that has limited effectiveness in

4 reduction of residues and the reduction does not correlate with solubility and polarity of

5 the compounds. This was also observed by Krol et al. (2000). Mechanical peeling, typical

6 for household processing and chemical peeling, applied mostly in industrial processing,

7 are the procedures which make a substantial contribution to reduction of residue levels in

8 the fruit flesh. The bulk of the residues are removed with the peel. Residues of systemic

9 pesticides penetrate into the plant tissues. Comparatively less of the systemic pesticide

10 residues are therefore removed with the peel. The relatively higher value of $\mathrm{P}_{2}$ calculated

11 after mechanical peeling (table 3) for the systemic fungicide procymidone, compared to

12 the other non-systemic compounds supports this concept. Chemical peeling results in the

13 same relative efficiency in residue reduction.

14

Thermal processing (cooking, sterilisation) may have highly variable effects depending on conditions (time, temperature, degree of moisture loss, whether the system is opened or closed) (Holland 1994) and on the properties of the compounds. Under the conditions of the boiling process, loss of the phosphorous compounds chlorpyrifos-methyl and fenitrothion occurred. Despite the loss of moisture the residue concentrations of both pesticides in concentrated puree were reduced significantly $\left(\mathrm{P}_{4}\right.$ values calculated for the step of concentration were 0.8 and 0.6 respectively). The effect of cooking temperature was the main reason for accelerating the loss of organophosphates, as these compounds are susceptible to volatilisation and hydrolysis under such conditions. 
1 The concentration procedure resulted in a substantial increase of procymidone and

2 vinclozolin residues $\left(\mathrm{P}_{4}\right.$ values calculated for the step of concentration were 2.3 and 4.5

3 respectively). Procymidone, derivative of dicarboximide and vinclozolin, an oxazolidine

4 derivative, are characterised by relatively high thermal stability (Tomlin 2000).

5

The process of sterilisation in hermetically closed jars did not further influence the residue levels of the pesticides studied. The reduction of residue concentrations resulting from the whole processing procedure of peeled fruits, calculated as final $\mathrm{P}$ value is significant, especially for chlorpyrifos-methyl and fenitrothion. The reduction of residues of these compounds in the final products was of the order of more than a hundred-fold (table 2).

The residues of procymidone and vinclozolin in the final products obtained through the processing of peeled fruit were reduced about ten times.

Processing of unpeeled fruit is substantially less effective in reducing the residue levels in final products. While the residues of organophosphates still undergo reductions of 2.5 to 5 times, vinclozolin residue levels in peach puree produced from unpeeled fruit does not change. The systemic fungicide procymidone is concentrated under this processing procedure $\left(\mathrm{P}_{\text {final. (unpeeled fruit) }}\right.$ is 1.3$)$.

All EC Directives concerning baby food safety stipulate that the exposure of infants and children to food contaminants is of particular concern because of their possible increased susceptibility for adverse effects. Growing and developing organisms have particular sensitivity to toxic compounds (Dencker et al. 1998, National Research Council 1993). The EC Directives on infant formulas and baby foods state that these products shall not 
1 contain any substance in such quantity as to endanger the health of infants and young

2 children.

3

4 As discussed above, detectable residues of the order of magnitude of the MRL may be

5 present in the particular crop at harvest. Procymidone residues of the order of magnitude

6 of $2 \mathrm{mg} / \mathrm{kg}$ could be expected in individual peach fruit. A compliance with the safety

7 requirements for general population of processed product (peach puree) may be expected

8 only in case when peeling procedure was carried out of the fruits treated with

9 procymidone. The same is valid for peaches treated with vinclozolin. Processing

10 procedures for pureeing are not effective enough to reduce the residues in the final

11 product to levels at/below the general MRL of $0.01 \mathrm{mg} \cdot \mathrm{kg}^{-1}$ established by the EC for any

12 individual pesticides in processed baby food. The results of the presented work indicate

13 that the processed foods based on peaches treated with procymidone and vinclozolin are

14 not suitable for feeding to infants and small children.

15

\section{Acknowledgement}

The financial support of NATO Program "Science for Peace" is highly acknowledged. 


\section{References}

European Commission 2002. Commission Directive 2002/63/EC. Official Journal of the European Communities L 187:30-43

European Commission 2003a Commission Directive 2003/13/EC, amending Directive 96/5/EC on processed cereal-based baby foods for infants and young children. Official Journal of the European Communities L 41:33-35

European Commission 2003b Commission Directive 2003/14/EC, amending Directive 91/321/EEC on infant formulae and follow-on formulae. Official Journal of the European Communities L 41:37-38

Dencker L.; Ericsson, P. 1998. Susceptibility in utero and upon neonatal exposure. Food Additives and Contaminants 15:37-43

Document SANCO/10476/2003. Quality Control Procedures for Pesticide Residues Analysis

Elkins E.R. 1989. Effect of commercial processing on pesticide residues in selected fruits and vegetables. Journal of the Association of Official Analytical Chemists 72:533-535

European Commission 2002. Informal co-ordination of MRLs established in Council Directives 76/895/EEC, 86/362/EEC, 86/363/EEC, 90/642/EEC

Hajslova J. 2000. Pesticides. In: Moffat C.F., Whittle K.J., editors. Environmental Contaminants in Food. Sheffield, CRC Press, 217-272

Holland P.T., Hamilton D., Ohlin B., Skidmore M.W. 1994. Effects of storage and processing on pesticide residues in plant products. Pure and Applied Chemistry $66: 335-356$ 
Joint Meeting of Pesticide Residues 2000. Pesticide residues in food. FAO Plant

Production and Protection Paper, 163, Rome

Krol W.J., Arsenault T.L., Pylypiw H., Incorvia Mattina M.J. 2000. Reduction of

Pesticide Residues on Produce by Rinsing. Journal of Agricultural and Food

Chemistry 48:4666-4670

Lentza-Rizos, C 2001. Consumers Risk Assessment for Pesticide Residues: Recent

Developments and their Implications for Mediterranean Countries. Phytoma 129:82-

90

National Research Council 1993. Pesticides in the diets of infants and children.

National Academy Press, Washington DC

Matsumura F. 2004. Contemporary Issues in Pesticide Risk Assessment.

Proceedings of the $15^{\text {th }}$ International Plant Protection Congress, Beijing, May 11-16, 236

Pappas C., Kyriakidis N.V., Athanasopulos P.E. 2003. Effects of storage conditions and fruit processing on the degradation of parathion-methyl on apples and lemons. Food Additives and Contaminants 20:375-379

Scattenberg H.J., Geno P.W., Hsu J.P., Fry W.G., Parker R.P. 1996. Effect of household preparation on levels of pesticide residues in produce. Journal of the Association of Official Analytical Chemists International 79:1447-1453

Tomlin C.D.S., editor 2000. The Pesticide Manual, Twelfth Edition, British Crop Protection Council

WHO Guidelines for predicting dietary intake of pesticide residues 1997. 2nd revised edition, GEMS/Food Document WHO/FSF/FOS/97.7, Geneva 
1 Table 1. Recoveries and standard deviations of fortified pesticides from peaches versus

2 matrix-matched standard calibration $(n=5)$

3

\begin{tabular}{|c|c|c|c|c|}
\hline \multirow{2}{*}{ Fortification } & \multicolumn{4}{|c|}{ Mean recovery \pm SD, \% } \\
\cline { 2 - 5 } & level, mg/kg & Fenitrothion & Procymidone & Vinclozolin \\
\hline 0.005 & $105 \pm 5.0$ & - & $96.7 \pm 7.6$ & $89.1 \pm 6.4$ \\
\hline 0.01 & $99.2 \pm 4.5$ & $98.2 \pm 13.9$ & $98.7 \pm 8.3$ & $72.3 \pm 6.8$ \\
\hline 0.02 & $90.4 \pm 6.9$ & $104 \pm 8.5$ & $96.9 \pm 5.5$ & $71.7 \pm 1.7$ \\
\hline
\end{tabular}

4 
Table 2. Residues at crucial steps of simulated industrial processing of peaches treated with pesticides (mean of 2 samples)

\begin{tabular}{|c|c|c|c|c|}
\hline \multirow{2}{*}{ Products } & \multicolumn{4}{|c|}{ Mean residues, $\mathrm{mg} / \mathrm{kg}$} \\
\hline & $\begin{array}{c}\text { Chlorpyrifos- } \\
\text { methyl }\end{array}$ & Fenitrothion & Procymidone & Vinclozolin \\
\hline Whole, unwashed, unpeeled fruit (1) & 1.1 & 2.7 & 4.5 & n.d. \\
\hline Whole, washed, unpeeled fruit (2) & 0.9 & 1.6 & 2.3 & 0.8 \\
\hline Puree of washed, mechanically peeled fruit (6) & 0.02 & 0.08 & 0.4 & 0.07 \\
\hline Peels of washed, mechanically peeled fruit (7) & 10.3 & 12.8 & 13.8 & 6.4 \\
\hline Puree of washed, unpeeled fruit (3) & 0.6 & n.d. & 1.5 & n.d. \\
\hline Puree of washed, unpeeled fruit, concentrated by boiling (4) & 0.2 & 1.1 & 2.9 & 1.0 \\
\hline Puree of washed, unpeeled fruit, concentrated, thermally sterilized (5) & 0.2 & 1.0 & 3.1 & 0.8 \\
\hline Puree of washed,chemically peeled fruit (8) & 0.009 & 0.09 & 0.1 & 0.02 \\
\hline Puree of chemically peeled fruit, concentrated by boiling ( 9 ) & 0.007 & 0.05 & 0.3 & 0.09 \\
\hline Puree of chemically peeled fruit, concentrated, thermally sterilized (10) & 0.007 & 0.03 & 0.3 & 0.08 \\
\hline
\end{tabular}

n.d. - no data 
Table 3. Processing factors of intermediate and final products of peach-based baby food puree

\begin{tabular}{|l|c|c|c|c|}
\hline \multirow{2}{*}{ Step } & \multicolumn{3}{|c|}{ Processing Factors (P)* } \\
\cline { 2 - 5 } & $\begin{array}{c}\text { Chlorpyrifos- } \\
\text { methyl }\end{array}$ & Fenitrothion & Procymidone & Vinclozolin \\
\hline $\mathrm{P}_{1}-$ Washing & 0.8 & 0.6 & 0.5 & \\
\hline $\mathrm{P}_{2}$ - Mechanical peeling & 0.02 & 0.05 & 0.2 & 0.09 \\
\hline $\mathrm{P}_{3}-$ Chemical peeling & 0.01 & 0.06 & 0.06 & 0.02 \\
\hline $\mathrm{P}_{4}-$ Concentration & 0.8 & 0.6 & 2,3 & 4.5 \\
\hline $\mathrm{P}_{5}-$ Sterilization & 1.0 & 1.0 & 1.0 & 0.9 \\
\hline $\mathrm{P}_{\text {final (chemical peeling) }}$ & 0.007 & 0.002 & 0.1 & 0.1 \\
\hline $\mathrm{P}_{\text {final (unpeeled fruit) }}$ & 0.2 & 0.4 & 1.3 & 1.0 \\
\hline
\end{tabular}

*Processing factors are calculated as ratio between the residues (R) in samples, taken at consecutive steps of processing shown in figure1:

$$
\begin{aligned}
& \mathrm{P}_{1}=\mathrm{R}_{(2)} / \mathrm{R}_{(1)} \\
& \mathrm{P}_{2}=\mathrm{R}_{(6)} / \mathrm{R}_{(2)} \\
& \mathrm{P}_{3}=\mathrm{R}_{(8)} / \mathrm{R}_{(2)} \\
& \mathrm{P}_{4}=\mathrm{R}_{(9)} / \mathrm{R}_{(8)} \\
& \mathrm{P}_{5}=\mathrm{R}_{(10)} / \mathrm{R}_{(9)} \\
& \mathrm{P}_{\text {final (chemical peeling) }}=\mathrm{R}_{(10)} / \mathrm{R}_{(2)} \\
& \mathrm{P}_{\text {final (unpeeled fruit) }}=\mathrm{R}_{(5)} / \mathrm{R}_{(2)}
\end{aligned}
$$


Figure 1.

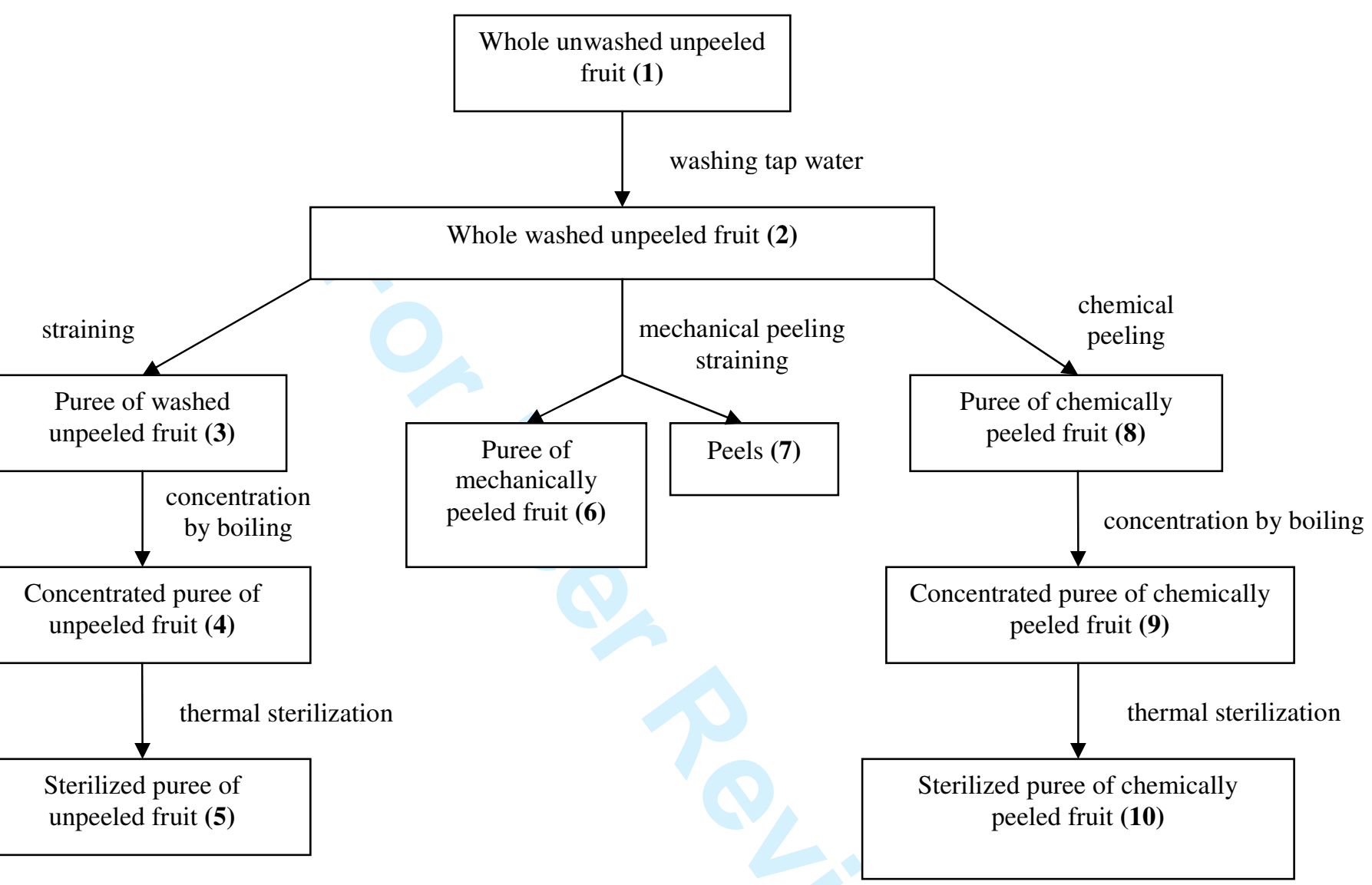


Figure 2
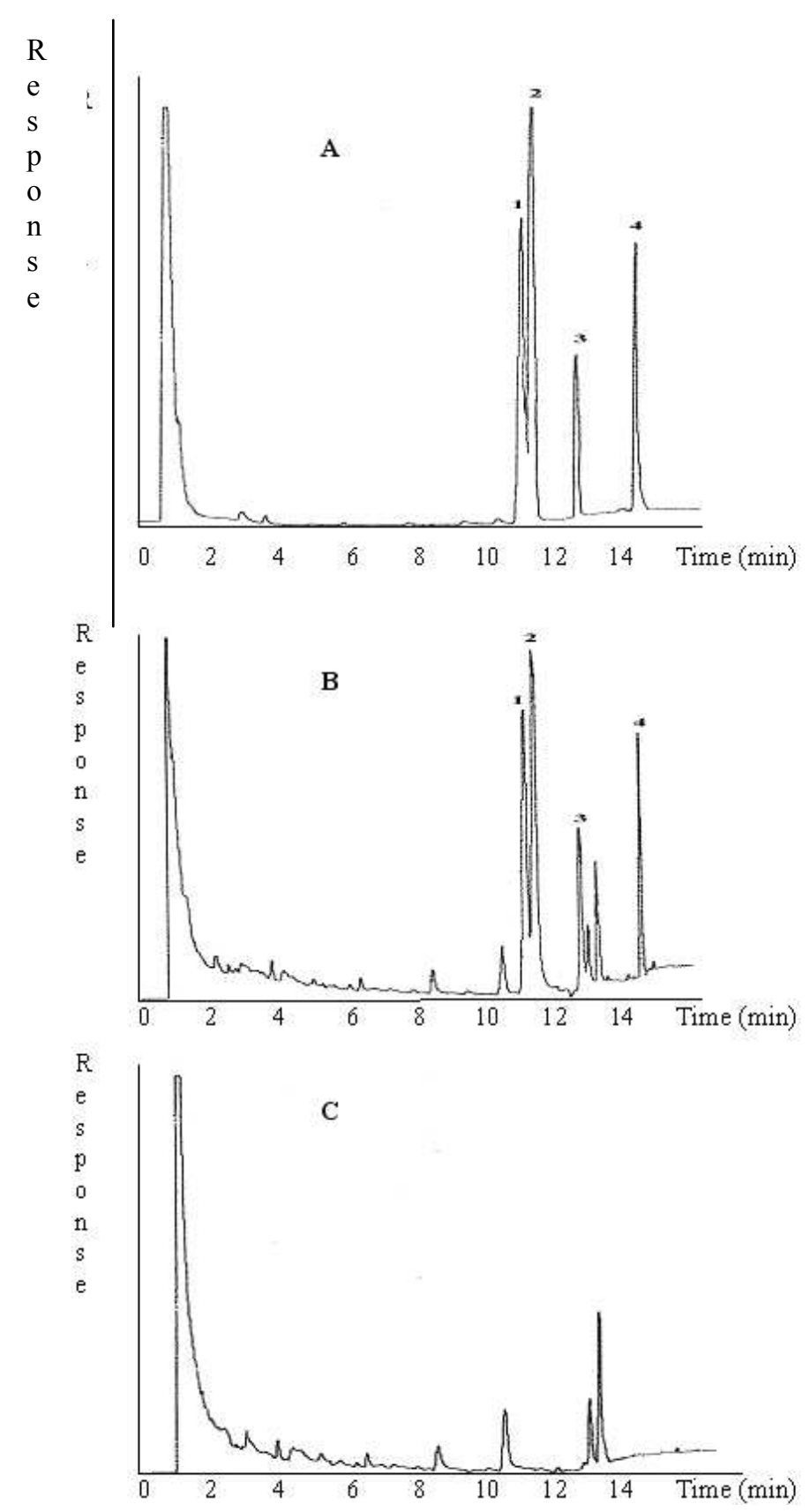
Figure captions

Figure 1. Crucial steps of peach processing and samples taken for analysis.

Figure 2. Chromatograms of mixed standard solution (A) at concentration $0.1 \mu \mathrm{g} / \mathrm{ml}$, extract of blank sample of peaches (B) subjected to the entire analytical procedure (matrix concentration $1 \mathrm{~g} / \mathrm{ml}$ ), recovery sample of peaches fortified at $0.1 \mathrm{mg} / \mathrm{kg}$ (matrix concentration $1 \mathrm{~g} / \mathrm{ml}$ ). Peak No: 1. chlorpiriphos-methyl, 2. vinclozolin, 3 fenitrothion, 4. procymidone. 